\title{
Knowledge of Stroke Risk Factors and Warning Signs among Private Primary School Teachers from Moro Community in Ife North Local Government, Nigeria
}

\author{
Article by Lamidi Rasheed Emmanuel ${ }^{1}$, Caleb A Adegbenro ${ }^{2}$ \\ ${ }^{1}$ Ph.D. in Public Health, Texila American University \\ ${ }^{2}$ Department of Community Health, College of Health Sciences, Obafemi Awolowo \\ University, Ile Ife, Osun State, Nigeria \\ Email: adelam77@yahoo.com ${ }^{1}$,calebade2012@yahoo.com ${ }^{2}$
}

\begin{abstract}
Background: Knowledge of stroke, especially the risk factors and warning signs is important in the control of the disease. This knowledge vary between patients and are difficult to interpret, especially for non-health professionals. The aim of the study is to evaluate the knowledge of stroke risk factors and warning signs among teachers in the private primary schools in Moro Community, Ife North Local Government, Osun State, Nigeria.

Methods: This study is a cross-sectional study design involving the use of pre-tested 43item, purpose designed, and self- administered questionnaires to collect information on knowledge of stroke risk factors and warning signs among the respondents. Data were collated and analyzed based on descriptive statistics.

Results: The result showed that the respondents generally demonstrated poor knowledge of risk factors (40.6\%) and warning signs of stroke (41.5\%). The most correctly identified risk factor of stroke was hypertension (73.3\%) while the least correctly identified risk factor of stroke were obesity (28.1\%) and increasing age (28.1\%). Difficulty in speech (70.2\%) was the most correctly recognized warning sign of stroke and the least correctly identified warning sign of stroke in this study was difficulty in understanding (31.6\%).

Conclusion: This study reveals a poor awareness of knowledge of stroke warning signs and risk factors among the private primary school teachers. Therefore, considerable education is needed to increase public awareness and health education on stroke.
\end{abstract}

Keywords: Stroke, warning signs, risk factors, teachers.

\section{Introduction}

Stroke, or a cerebrovascular accident (CVA), is the irreversible damage caused to the brain resulting from a thrombotic, embolic or haemorrhagic event. It is one of the most common neurological disorders in clinical practice and the leading cause of adult disability. According to World Health Organization (WHO), it is the second commonest cause of death worldwide (Bonita et al, 2004). In 2005, stroke deaths accounted for $87 \%$ of deaths in developing countries and an estimated 5.8 million people died from stroke worldwide (Strong et al, 2007).

Stroke is one of the non-communicable diseases (NCD) and it is on the rise globally especially in the low and middle-income countries where initially it was assumed the burden of these diseases was uncommon (WHO, 2006). Stroke is also the most preventable neurological disease, and this is mainly because, many of its risk factors such as hypertension, high cholesterol, diabetes and smoking can be prevented either through healthier lifestyle choices or by medication (Sacco, 1997).

There are number of signs and symptoms of stroke but the followings are the major important signs and symptoms of stroke: (i) Sudden numbness or weakness of the face, arm, or leg, especially on one side of the body; (ii) Sudden confusion or trouble speaking or understanding speech; (iii) Sudden trouble seeing in one or both eyes; (iv) Sudden trouble walking, dizziness, or loss of balance or coordination; and (v) Sudden severe headache with no known cause, 
unconsciousness, nausea, and vomiting (Greenlund, Neff, Zheng et al., 2003; Flaherty, Kleindorfer, \& Kissela, 2004).

Studies have shown that lack of recognition of stroke warning signs is an important causal factor of delay in hospital reporting of stroke (Williams, 1997; Pontes-Neto, 2008). To combat the effects of stroke, the time from the onset of stroke symptoms to hospital arrival must be improved in order to provide timely and effective treatment. Many factors contribute to delays in seeking treatment for stroke, but the principal factor is believed to be a lack of public knowledge regarding stroke symptoms and the need for a rapid response (Evenson, 2001; Yoon, 2001).

Previous studies have revealed that an important proportion of stroke high-risk patients are unaware of their risk (Stroebele et al, 2011; Al Shafaee, 2006). Knowledge of stroke risk factors might improve primary prevention through lifestyle modifications and a more efficient control of cardiovascular risk factors (Stroebele, 2011). The success of any disease control programme depends on community knowledge and practices as regards to risk factors, treatment and prevention. It is envisaged that high knowledge and awareness of these conditions will prompt people to seek healthcare timely and reduce possibilities of developing complications. Several studies have documented that lack of community awareness on communicable diseases could contribute to the spread of the diseases, hinder control strategies and increase risk of exposure to the diseases (Mboera et al., 2009; Imbahale et al., 2010).

Stroke symptoms are multiple and complex, they vary between patients and are difficult to interpret, especially for non-health professionals, also due to situational and contextual influences (Jones et al. 2010; Lecouturier, Murtagh, et al. 2010).

The purpose of this study, therefore, is to evaluate the knowledge of risk factors as well as warning symptoms of stroke among teachers in the private primary schools in Moro Community at Ife North Local Government, Osun State, Nigeria.

The objectives were:

1. To assess the knowledge of risk factors among teachers in private primary schools from Moro Community in Ife North Local Government.

2. To assess the knowledge of warning symptoms of stroke among teachers in the selected private primary schools.

\section{Methodology}

\section{Study location}

The study was carried out among the teachers in the four selected private primary schools from Moro Community in Ife North Local Government Area, Osun State, South West, Nigeria. The headquarters of this Local Government is at Ipetumodu and it has adjoining boundary with Ife Central Local Government situated in the ancient city of Ile Ife known as cradle of Yoruba.

\section{Study design}

The study was conducted as a descriptive, cross-sectional survey among teachers in the private primary schools from Moro Community in Ife North Local Government, Osun State, Nigeria in June, 2017.

\section{Sampling technique}

A sample of convenience was used for the study. Four out of 10 private primary schools in Moro Community of Ife North Local Government were randomly selected for the study

\section{Sample size determination}

All the 57 teachers that were available at the time of the study in all the four selected schools were recruited, through convenient sampling technique, as sample size for the study. 


\section{Survey instrument}

A closed-ended, pre- tested, self-administered, 43 item questionnaire was used to collect data on stroke knowledge of warning signs and risk factors from the respondents.

\section{Questionnaire design}

Most of the questions for this study have already been used in previous studies (Pontes-Neto et al, 2008; Yoon and Byle, 2002; Sug et al, 2001). Questionnaire was divided into three parts; the first part was about the demographic information of the participant, the second part was about respondents' knowledge of warning signs of stroke and the third part was about knowledge of risk factors of stroke.

\section{Inclusion criteria}

The study was delimited to teachers who are teaching in selected private primary schools from Moro Community, Ife North Local Government Area in Osun State, South West, Nigeria.

\section{Exclusion criteria}

Teachers with a past history of stroke were excluded from the study as it was assumed that they would have a better knowledge of stroke warning signs and risk factors having suffered from the disease before.

\section{Data analysis procedures}

Filled questionnaires were, first of all, coded before entering into the computer and data analysis were performed using Statistical Package for Social Sciences (SPSS) version 22. Descriptive statistics of frequencies and percentages was used to summarize the data on demographic characteristics (age, gender, educational level, marital status, religion and years of teaching experience), knowledge of stroke risk factors and knowledge of stroke warning signs. The result was also presented using tables, bar and pie charts.

\section{Ethical consideration}

Ethical clearance was sought from Obafemi Awolowo University Teaching Hospital Ethical Review Board before the study was conducted. Permission was also sought from the Local Inspector of Education and Head teacher of each school. Individual informed consent was also obtained from each teacher.

\section{Result}

\section{Demographic characteristic of the participants}

A total of 57 teaching members of staff at four selected private primary schools from Moro Community in Ife North Local Government participated in the study. Majority $(84.2 \% ; n=48)$ of the participants were females (Figure 1). The age group 25-44 years $(91.2 \% ; n=52$ ) constituted the majority of the respondents. Most $(75.4 \% ; n=43)$ of the study participants were with National Certificate of Education/Diploma as educational qualification and have mostly less than 5years of working experience $(61.4 \%$; $n=35)$ as teachers. The respondents were majorly Christians $(93.0 \% ; n=53)$ and not yet married $(56.1 ; n=32)$. (Table 1$)$. 
DOI: $10.21522 /$ TIJPH.2013.05.04.Art067

ISSN: $2520-3134$

Table 1. Descriptive statistics of socio-demographic factors among the respondents s $(n=57)$

\begin{tabular}{|l|l|}
\hline Variables & $\mathrm{N}(\%)$ \\
\hline Age: & $52(91.2)$ \\
$25-44$ & $5(8.8)$ \\
$45-64$ & \\
Gender: & $9(15.8)$ \\
Male & $48(84.2)$ \\
Female & \\
Marital Status: & $32(56.1)$ \\
Single & $25(43.9)$ \\
Married & \\
Years of Experience: & $274(74.7)$ \\
Less than 5 years & $39(10.6)$ \\
5- 10 years & $7(1.9)$ \\
More than 5 years & \\
Educational level: & $9(15.8)$ \\
School Certificate & $43(75.4)$ \\
NCE/Diploma & $5(8.8)$ \\
Degree & \\
Religion: & $53(93.0)$ \\
Islam & $4(7.0)$ \\
Christianity & \\
\hline
\end{tabular}

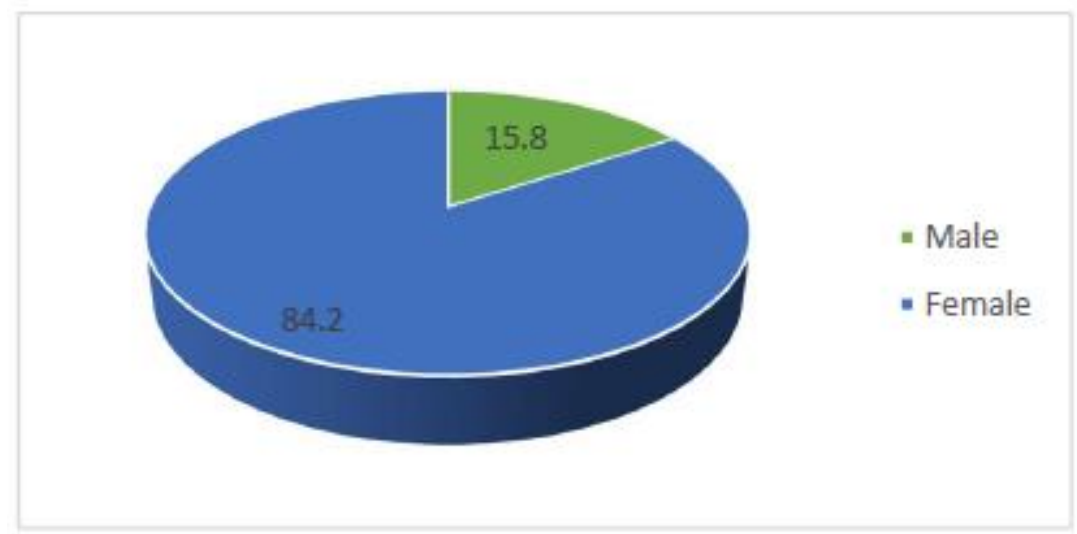

Figure 1. Gender distribution of the respondents

\section{Knowledge of warning signs of stroke among the respondents}

The ability of the respondents to identify warning signs for stroke are summarized in Table 2. The overall knowledge of warning signs of stroke demonstrated by the participants was very poor and below average $(41.5 \%)$. Difficulty in speech was the most identified warning sign of stroke in this study $(70.2 \% ; \mathrm{n}=40)$ while difficulty in understanding was the least often identified warning sign of stroke $(31.6 \% ; n=18)$. Next to this, sudden headache was correctly identified by twenty seven $(40.4 \%)$ participants while visual problems were identified correctly as warning signs of stroke by twenty three $(47.4 \%)$ of them. Thirty one $(54.4 \%)$ of the participants correctly identified dizziness as warning sign of stroke whereas loss of balance was identified correctly as stroke warning signs by thirty two $(56.1 \%)$ participants. Numbness and mouth deviation as warning signs of stroke were correctly identified by thirty three $(57.9 \%)$ participants (Figure 2). 
Table 2. Knowledge of warning signs of stroke among the respondents $(n=57)$

\begin{tabular}{lll}
\hline \multicolumn{1}{c}{ Variables } & Correct & Incorrect \\
\hline & $\mathrm{N}(\%)$ & $\mathrm{N}(\%)$ \\
Numbness & $33(57.9)$ & $24(42.1)$ \\
Dizziness & $31(54.4)$ & $26(45.6)$ \\
Visual Problems & $27(47.7)$ & $30(52.6)$ \\
$\begin{array}{l}\text { Difficulty in } \\
\text { Understanding }\end{array}$ & $18(31.6)$ & $39(68.4)$ \\
Speech Difficulty & $40(70.2)$ & $17(29.8)$ \\
Sudden Headache & $23(40.4)$ & $34(59.6)$ \\
Mouth Deviation & $33(57.9)$ & $24(42.1)$ \\
Loss of Balance & $32(56.1)$ & $25(43.9)$ \\
Overall knowledge of warning signs of & $41.54 \pm$ \\
stroke: Mean \pm Standard deviation & 15.80 \\
\hline
\end{tabular}

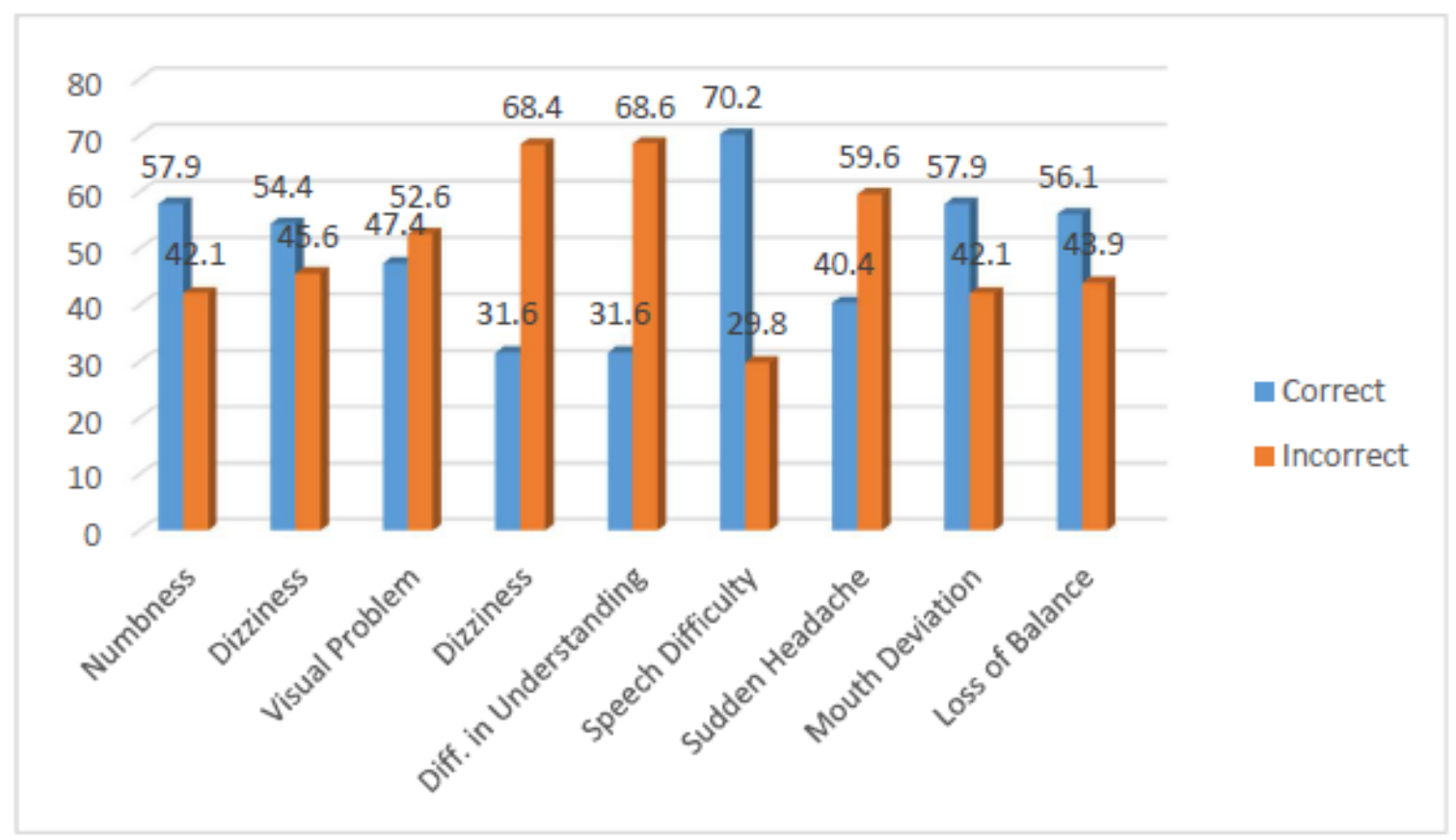

Figure 3. Knowledge of warning signs of stroke among the respondents

\section{Knowledge of risk factors of stroke among the respondents}

The ability of the respondents to identify risk factors for stroke are summarized in Table 3 . The overall knowledge of risk factors for stroke as demonstrated by the participants was equally poor and below average $(40.6 \%)$. The most identified risk factor of stroke in the study was hypertension $(73.7 \%)$ followed by high cholesterol $(68.4 \%)$ and excessive alcohol (54.4\%). The least often identified risk factor in this study were obesity $(28.1 \%)$ and increasing age $(28.1 \%)$. Smoking was correctly recognized by $43.2 \%$ of participants as risk factor of stroke. Also, poor eating, diabetes and lack of exercise were identified as risk factors of stroke in this study by $42.1 \%, 35.1 \%$ and $29.8 \%$ respondents respectively. Family history of stroke was correctly identified as risk factor of stroke by $36.8 \%$ participants while $35.1 \%$ of the participants recognized correctly past history of heart disease as risk for of stroke in the study (Figure 3). 
DOI: $10.21522 /$ TIJPH.2013.05.04.Art067

ISSN: $2520-3134$

Table 3. Knowledge of risk factors of stroke among the respondents $(n=57)$

\begin{tabular}{llc}
\hline Variables & Correct & Incorrect \\
\hline Obesity & $16(28.1)$ & $41(71.9)$ \\
Diabetes & $20(35.1)$ & $37(64.9)$ \\
Poor Eating & $24(42.1)$ & $33(57.9)$ \\
Excessive Alcohol & $31(54.4)$ & $26(45.6)$ \\
Hypertension & $42(73.7)$ & $15(26.3)$ \\
High Cholesterol & $39(68.4)$ & $18(31.6)$ \\
Smoking & $27(47.4)$ & $30(52.6)$ \\
Lack of Exercise & $17(29.8)$ & $40(70.2)$ \\
Increasing Age & $16(28.1)$ & $41(71.9)$ \\
Family History of & & $36(63.2)$ \\
Stroke & $21(36.8)$ & \\
$\quad$ Past History of & & $37(64.9)$ \\
Heart Disease & $20(35.1)$ & $40.63 \pm$ \\
$\quad$ Overall knowledge of risk factors of \\
stroke: Mean \pm Standard deviation & 18.14
\end{tabular}

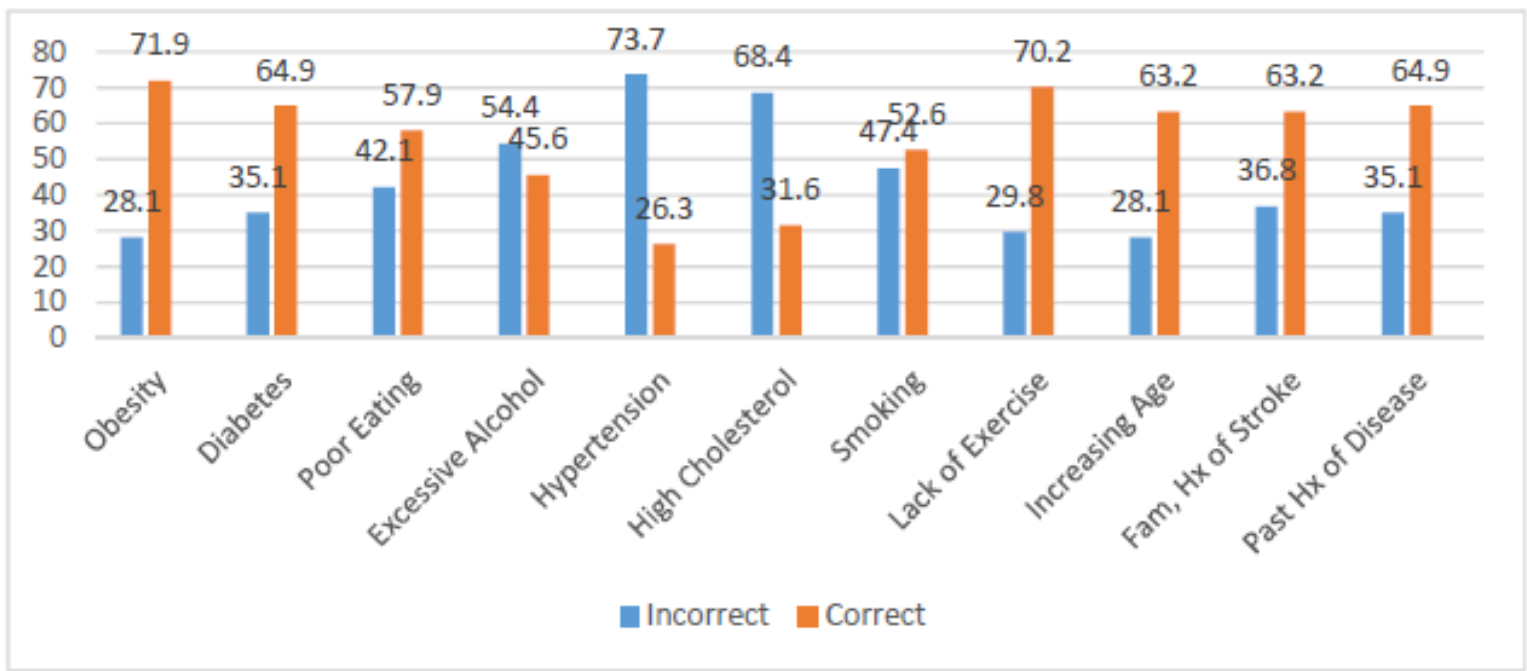

Figure 3. Knowledge of risk factors of stroke among the respondents

\section{Discussion}

This study was conducted to assess the knowledge of stroke risk factors and warning signs among teachers in the private primary schools in Moro Community, Ife North Local Government, Osun State, Nigeria. The sex distribution in this study had more female respondents than male respondents. This can be connected to the fact that female teachers show more interest in caring for children and teaching in elementary schools are still seen as a woman's job (Coffey and Delamont, 2000). Also, the result of this study showed that the teachers in these schools are predominantly christians (93.0\%). This may be attributed to the fact that possibly the owners of these private primary schools are christians and they might have decided to employ mostly christians to work in their schools or probably that only christian teachers have decided to seek employment in those schools having known that the schools are owned by christians.

The percentage knowledge of stroke risk factors in this study ranges from $28.1 \%$ to $73.7 \%$. This result is almost similar to results obtained from previous studies. Most studies reported percentages that range from 40 to 79\% (Schneider et al, 2003; Pandian et al, 2005; Pontes-Neto et al, 2008). Kothari et al, 1997 in their study stated that up to $25 \%$ did not know a single risk factor for stroke. 
The most identified risk factor of stroke in this study was hypertension (73.7\%). This result is very similar to findings of other studies. Kattapong et al. (1998) stated that $97 \%$ identified hypertension as a stroke risk factors while diabetes mellitus, was only identified by $63 \%$. In this study, high cholesterol was identified to be next to hypertension. Both were the most frequently named risk factors as supported by other studies. Results from other studies have already revealed that these two risk factors are among the most perceived as stroke risk factors (Hickey et al, 2009; Carroll et al, 2004; Reeves et al, 2002).

This study revealed that the overall knowledge of warning signs of stroke demonstrated by the participants was very poor and below average $(41.5 \%)$, but on the contrary, Pancioli et al, 1998 cited that only $57 \%$ of their sample could correctly identify a warning sign of stroke. In addition, in this study, difficulty in speech was the most identified warning sign of stroke (70.2\%) with difficulty in understanding being the least (31.6\%). This result is similar to other community-based studies which presented lower percentages that range 30 to $70 \%$ (Sug et al, 2001; Pancioli et al, 1998 Mukulik et al, 2008; Pandian, 2005). Kothari et al, 1997 in their study stated that up to $27 \%$ of the adult population did not know a sign or symptom of a stroke.

Finally, it is evident from findings in this study that majority of teachers in the private primary schools in Moro community, Ife North Local Government, have poor knowledge of stroke warning signs and risk factors. However, it is actually expected that the knowledge of the warning signs and risk factors of stroke would be as high as possible among these participants considering the fact that these respondents were among the highly educated and professional population. It is, therefore, important that these professionals are appropriately educated as regards stroke and other non-communicable diseases as they may serve as key advocacy group to the community and also serve as policy makers in Nigeria. In the future, the data obtained from this study can be utilized to develop an education program designed to address the specific areas of stroke knowledge deficits.

\section{Study limitation}

1. This study focused on teachers in the private primary schools from Moro Community in Ife North Local Government, Osun State, therefore, finding may not be generalized to the entire school teachers population in Osun State.

2. Problem of potential selection bias because participants for the study were consenting individuals and they differ from non-consenting individuals.

3. Due to the fact that the data were self-reported, the answers are subject to recall bias and overreporting or under-reporting of behaviors and existing disease.

\section{Conclusion}

The outcome of this study showed that knowledge gap on stroke exists amongst the private primary school teachers in Moro Community, Ife North Local Government, and Nigeria. Also, knowledge of stroke warning signs and risk factors are much poorer than expected. Therefore, the enormous work to be involved in creating awareness, conducting health education and organizing public enlightenment programmes on knowledge of stroke warning signs and risk factors among the teachers in schools cannot be overemphasized.

\section{References}

[1].Al Shafaee MA, Ganguly SS, Al Asmi AR (2006). Perception of stroke and knowledge of potential risk factors among Omani patients at increased risk for stroke. BMC Neurology, 6:38.

[2].Anshenden R, Silagy C, Weller D (1997). A systematic review of the effectiveness of promoting lifestyle change in general practice. Fom Pratt; 14:160-76.

[3].Bonita R, Mendis S, Truesen T (2004). The global stroke initiative. Lancet Neurol; 3: 391-3.

[4].C K, Fruin M, Gooding T, Tirschwell D, Love P, Mankowski T (2001). Community- based education improves very important for early management20. Conclusion stroke knowledge. Cerebrovasc Dis; 11 (1): 34-43.

[5].Carroll C, Hobart J, Fox C, Teare L, Gibson J (2004). Stroke in Devon: knowledge was good, but action was poor. Journal of Neurology, Neurosurgery and Psychiatry; 75: 567-71. 
DOI: $10.21522 /$ TIJPH.2013.05.04.Art067

ISSN: $2520-3134$

[6].Coffey, A \& Delamont, S. (2000). Feminism and the classroom teacher. London: Routledge/Falmer.

[7].Evenson KR, Rosamond WD, Morris DL (2001). Pre-hospital and inhospital delays in acute stroke care. Neuroepidemiology; 20: 65-76.

[8].Flaherty, M.L., Kleindorfer, D and Kissela, B.M. (2004). Public stroke awareness and education. Journal of Cerebrovascular Diseases, 3 (4): 130-133.

[9].Goldstein LB, Adams R, Becker K, Furberg CD, Gorelick PB, Hademenos G, et al (2001). Primary prevention of ischemic stroke: a statement for healthcare professionals from the Stroke Council of the American Heart Association. Stroke; 32(1): 280-99.

[10]. Greenlund, K.J., Neff, L.J., Zheng, Z.J., Keenan, N.L., Giles, W.H., Ayala, C.A., Croft, J.B., Mensah, G.A. (2003). Low public recognition of major stroke symptoms. American Journal of Preventive Medicine, 25 (4): 315-319.

[11]. Hickey A, O'Hanlon A, McGee H, et al (2009). Stroke awareness in the general population: knowledge of stroke risk factors and warning signs in older adults. BMC Geriatrics; 9: 35.

[12]. Imbahale, S.S., Fillinger, U., Githeko, A., Mukabana, W.R., Takken, W. (2010). An exploratory survey of malaria prevalence and people's knowledge, attitudes and practices of mosquito larval source management for malaria control in western Kenya. Acta Tropica115, 248-256.

[13]. Jones, S.P. et al., 2010. Stroke knowledge and awareness: an integrative review of the evidence. Age and Ageing, 39 (1): 11-22.

[14]. Kattapong, V., Loogstreth, W., Kuku U, W., Howard, D., Bowes, J., Wilson, S., Bigney. \& Becker, T. (1998). Stroke risk factor knowledge in Hispanic and non-Hispanic white women in New Mexico: Implications for targeted prevention strategies. Healthcare for Women International. 19. 311-325.

[15]. Kish, L (1985). Survey Sampling. New York: John Wiley and Sons, Inc.

[16]. Lecouturier, J., Murtagh, M.J., et al (2010). Response to symptoms of stroke in the UK: a systematic review. BMC Health Services Research, 10: 157.

[17]. Mallick A, O'Callaghan F (2010). Risk factors and treatment outcomes of childhood stroke. Expert Rev Neurother; 10 (8):1331-46. 11.

[18]. Mboera, L.E.G., Shayo, E.H., Senkoro, K.P., Rumisha, S.F., Mlozi, M.R.S., Mayala, B.K (2010). Knowledge, perceptions and practices of farming communities on linkages between malaria and agriculture in Mvomero District, Tanzania. Acta Tropica 113, 139-144.

[19]. Mikulik R, Bunt L, Hrdlicka D, Dusek L, Vaclavik D, Kryza J (2008). Calling 911 in response to stroke: a nationwide study assessing definitive individual behavior. Stroke; 39: 1844-9.

[20]. Pancioli, A, Broderick, J, Kothari, R, Brott, T, Tuchfarber, A, Miller, R, Khoury, J, \& Jauch, E. (1998). Public perception of stroke warning signs and knowledge of potential risk Êictors. JAMA. 279.1288-1292.

[21]. Pandian JD, Jaison A, Deepak SS, Kalra G, Shamsher S, Lincoln DJ, Abraham G (2005). Public awareness of warning symptoms, risk factors, and treatment of stroke in Northwest India. Stroke, 36:644-648.

[22]. Pontes-Neto OM, Silva GS, Feitosa MR, de Figueiredo NL, Fiorot JA Jr, Rocha TN, Massaro AR, Leite JP (2008). Stroke awareness in Brazil: alarming results in a community-based study. Stroke, 39:292-296.

[23]. Reeves MJ, Hogan JG, Rafferty AP. Knowledge of stroke risk factors and warning signs among Michigan adults. Neurology 2002; 59: 1547-52.

[24]. Sacco RL, Benjamin EJ, Broderick JP, Dyken M, Easton JD, Feinberg WM, Goldstein LB, Gorelick PB, Howard G, Kittner SJ, Manolio TA, Whisnant JP, Wolf PA (1997). American heart association prevention conference, IV: prevention and rehabilitation of stroke: risk factors. Stroke, 28:1507-1517.

[25]. Samsa GP, Cohen SJ, Goldstein LB, et al (1997). Knowledge of risk among patients at increased risk for stroke. Stroke; 28: 916-21.

[26]. Schneider AT, Pancioli AM, Khoury JC, et al (2003). Trends in community knowledge of the warning signs and risk factors for stroke. JAMA; 289: 343-6.

[27]. Stroebele N, Muller-Riemenschneider F, Nolte CH, Muller-Nordhorn J, Bockelbrink A, Willich SN (2011). Knowledge of risk factors, and warning signs of stroke: a systematic review from a gender perspective. International Journal of Stroke; 6: 606.

[28]. Strong K, Mathers C, Bonita R (2007). Preventing stroke: saving lives around the world. Lancet Neurol; 6:182-87.

[29]. Sug Yoon S, Heller RF, Levi C, Wiggers J, Fitzgerald PE (2001). Knowledge of stroke risk factors, warning symptoms, and treatment among an Australian urban population. Stroke; 32: 1926-1930. 
Texila International Journal of Public Health

Volume 5, Issue 4, Dec 2017

[30]. WHO (2006). An Estimation of the economic impact of chronic non-communicable diseases in selected countries. World Health Organization, Geneva.

[31]. Williams LS, Bruno A, Rouch D, Marriott DJ (1997). Stroke patients' knowledge of stroke. Influence on time to presentation. Stroke, 28: 912-915.

[32]. Yoon SS, Byles J (2002). Perceptions of stroke in the general public and patients with stroke: a qualitative study. BMJ; 324: 1065-1068.

[33]. Yoon SS, Heller RF, Levi C, Wiggers J, Fitzgerald PE (2001). Knowledge of stroke risk factors, warning symptoms and treatment among an Australian urban population. Stroke; 32: 1926-30. 